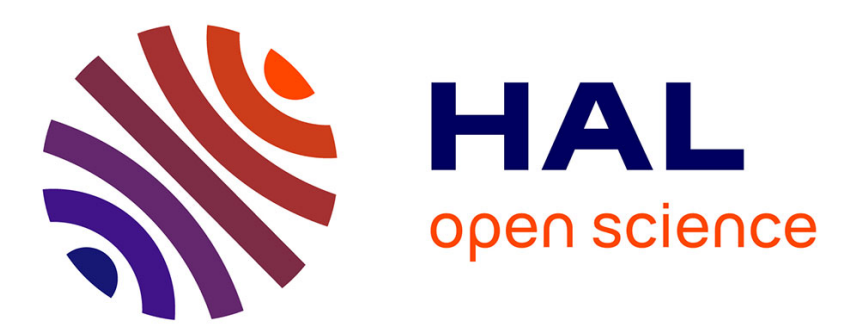

\title{
An approach for steering products and services offering variety towards economic and environmental sustainability
}

Khaled Medini, Xavier Boucher

\section{- To cite this version:}

Khaled Medini, Xavier Boucher. An approach for steering products and services offering variety towards economic and environmental sustainability. CIRP Journal of Manufacturing Science and Technology, 2016, 15, pp.65-73. 10.1016/j.cirpj.2016.04.009 . emse-01316798

\section{HAL Id: emse-01316798 \\ https://hal-emse.ccsd.cnrs.fr/emse-01316798}

Submitted on 12 Aug 2021

HAL is a multi-disciplinary open access archive for the deposit and dissemination of scientific research documents, whether they are published or not. The documents may come from teaching and research institutions in France or abroad, or from public or private research centers.
L'archive ouverte pluridisciplinaire HAL, est destinée au dépôt et à la diffusion de documents scientifiques de niveau recherche, publiés ou non, émanant des établissements d'enseignement et de recherche français ou étrangers, des laboratoires publics ou privés.

\section{(c)(1)}

Distributed under a Creative Commons Attribution| 4.0 International License 


\title{
An approach for steering products and services offering variety towards economic and environmental sustainability
}

\author{
Khaled Medini *, Xavier Boucher \\ Univ Lyon, Mines Saint-Etienne, Henri Fayol Institute, CNRS, UMR 5600 EVS, 158 cours Fauriel, F42023 Saint-Etienne, France
}

Customers' individual preferences are calling for greater variety of firms' offerings. Faced with this situation, firms endeavour to meet customer requirements while reducing their costs and impact on the environment to remain competitive. The attainment of these goals entails various issues that must be addressed including multiple performance drivers and criteria relating to environmental and economic sustainability and variety. Accordingly, trade-offs must be defined and balanced among such heterogeneous criteria to facilitate the decision-making process on a variety of levels regarding environmental and economic sustainability. These trade-offs should involve decision makers to reflect the firm's priorities and consider its business field. This paper proposes an approach supporting the decision-making process on offering variety to the market while considering environmental and economic sustainability criteria. More specifically, the approach uses economic and environmental performance indicators and inputs from decision makers to determine the variety of the offering to meet a given demand. The paper highlights the impact of variety steering on environmental and economic sustainability indicators.

\section{Introduction}

The increasing customer demand for tailored solutions compels firms to seek customer satisfaction more effectively, thus broadening the conventional focus on productivity to integrate customer expectations and satisfaction. This has led to more customer-centred strategies in both Business to Customer (B2C) and Business to Business (B2B) contexts, including Mass Customization (MC) and Product-Service Systems (PSS). Whereas MC aims to fulfil individual customer needs with near-mass-production efficiency [1], product service systems aim to offer a solution with a combination of products and services that satisfies an identified customer need [2]. Therefore, MC and PSS are well suited for current markets in multiple sectors. Customers' individual preferences are calling for more variety of firms' offerings in terms of products and services. Under these circumstances, firms endeavour to meet diversified customer demands while reducing their internal costs and impact on the environment to remain competitive. Achieving such a goal entails various issues be addressed such as the heterogeneity of the multiple performance

\footnotetext{
* Corresponding author. Tel.: +33 47742 9317; fax: +33 0477426633. E-mail address: khaled.medini@emse.fr (K. Medini).
}

drivers and criteria relating to environmental and economic sustainability and variety. Accordingly, trade-offs must be defined and balanced between such heterogeneous criteria to facilitate the decision-making process on variety levels regarding the environmental and economic sustainability impact. The key point is how to maintain a good a level of variety in the offering at a reasonable cost and relatively low environmental impact. Obviously, defining trade-offs regarding these two rather conflicting objectives first requires involving the decision makers to reflect firm priorities and consider its business field.

This paper proposes a model supporting the decision-making process on various solutions delivered to the market while considering environmental and economic sustainability criteria. More specifically, the model uses performance indicators calculated by life cycle assessment tools, applies weights to these indicators, and finally balances the production among variants to meet given demand requirements. The paper highlights the impact of variety steering on environmental and economic sustainability indicators. The remainder of this paper is organized as follows: section "State of the art" provides an overview of product variety, followed by an environmental and economic sustainability assessment, which are the two objectives to be reconciled. The proposed approach is presented in section "Proposed approach". An illustrative case study is presented and discussed in section 
"Illustrative case study". Section "Discussion" discusses the addedvalue and limitations of the proposed model. The paper ends with concluding remarks in section "Conclusion".

\section{State of the art}

The multifaceted problem addressed by this paper requires a multidisciplinary approach that provides valuable decision support to companies that encounter this problem. Subsequently, three literature streams are required to set the foundations of the proposed approach. Section "Impact of offering variety on products and product-service production systems" identifies some of the most common impacts of variety on production systems. Section "Green considerations in operation management" elaborates on the need for and underlying approaches of mitigating the impact of variety on production systems. Section "Business considerations in operation management" provides an overview of environmental and economic sustainability impact optimization in production systems. The aim is to explore existing models and tools used to assess the economic and environmental sustainability of a given product offering characterized with a certain variety level. Because the assessment and optimization of economic and environmental sustainability of a product offering entails multiple criteria, proper decision-making procedures are required to provide valuable support for decision makers. In this vein, section "Decision-making and indicator aggregation" discusses some solution approaches for the multi-criteria decision-making problem. A summary of the findings of the literature review is presented in section "Summary of the state of the art".

\section{Impact of offering variety on products and product-service production systems}

Increasing the variety of products and services has been shown to be an answer to diversified demands that shape current product and service markets. From a mere product perspective, variety refers to the diversity of products that a production system provides to the marketplace [3]. The manufacturing sector has witnessed a shift from conventional channels of product sales to a new paradigm in which the product is integrated with a set of services to maximize the added value and meet specific customer demands [4]. This paradigm shift has led to the emergence of PSS. According to Goedkoop et al. [5, p. 18], a PSS is a marketable set of products and services capable of jointly fulfilling a user's need. Subsequently, product variety cannot be decoupled from service variety because the product and service can be equally important for the function fulfilment. Therefore, many firms have recognized the need for increasing the variety of their offering (including products and services and integrated solutions) to increase their attractiveness [6,7].

The other side of variety relates to the complexity induced by the high number of product and service variants. Product complexity can be approached by the degree to which the individual parts/subassemblies have physical attributes that cause difficulties during the handling and insertion processes in manual or automatic assembly [8]. Obviously, increasing the number of product and service variants to meet as many customer requirements as possible is likely to induce an increase in the number of components, modules, process sequences, service delivery activities, operators, and suppliers [8,9]. This involves additional efforts on the part of the operators to move from one variant to another during production (because activity sequences, tools and raw materials, for example, are not similar among the variants) or deliver a variety of services requiring each specific qualification. Consequently, the increased variety may burden the cost benefits of scale production owing to lower production lot sizes, high change over time and heavy workload, in terms of quantity (e.g., demand for service) and quality (e.g., required qualification), to ensure good service quality. The variety level of supplied components or modules also impacts the supply cost by increasing the unit cost with decreasing purchased lot size because companies must be able to efficiently produce, sort, ship and deliver small quantities of highly differentiated products [10]. These impacts on cost go hand in hand with the variety impact on lead time. Basically, the variety-induced complexity in the production systems extends the setup times and introduces some stochastic aspects in the production lead times depending on the level of customization of each product variant [11]. The scarcity of some supplied or outsourced components implies higher average lead time of the variant(s) using those components. Obviously, this problem also impacts service delivery performance, particularly for services that require components to be delivered (spare parts, consumables, etc.). All of these factors violate the rationale of variety, which is to efficiently (in terms of time and cost) meet customers' diversified demands. Furthermore, the offering of high variety has an effect on the overall environmental impact of a given mix of products or services because of the lack of resource sharing. For instance, the process variety induced by product variety calls for more flexibility of the production system. Although flexibility simplifies working with a wide variety of customer orders, it may entail more energy and material consumption. The point is that manufacturing modular products or processes (typically used in flexible and reconfigurable manufacturing systems), for instance, may require more material and energy than manufacturing conventional products and processes [12]. This means that the variety of the offering must be properly steered towards the objectives of the company and should not be seen as goal in itself.

Whereas variety is seen as a way to meet specific customer demands, it has been emphasized that too much variety confuses customers [13]. Hence, the benefits generated by variety may not keep pace with the increasing customer demands of products and services. Gardner [14, p. 55] argued that it is often best to offer a feature or option to make the offering relevant to the marketplace, not merely because the company can offer it. Additionally, careful decisions must be made regarding what to offer to the market because of the capacity burdens within each company.

From a green perspective, managing the overall environmental impact of a high-variety mix of products or services can be challenging because of the growing number of SKU (stock keeping unit) types. In fact, each SKU has a specific environmental impact that is usually decoupled from the demand for that specific SKU. For example, a given SKU may have a high greenhouse gas impact (e.g., because of the raw material extraction method) but have only a minor demand. At this point, it is convenient to consider this impact when defining the variety level of the offering. The service delivery activities may also have various impacts on both the environment and costs, depending on the consumables, transportation means, distance to customer premises, and qualification of the service operators (and thus unit costs).

\section{Green considerations in operation management}

The emergence of green considerations in operation management is witnessed by the large body of literature relating to this topic, which involves typically the question of trade-offs between environmental and business concerns $[15,16]$.

Environmental sustainability is increasingly emerging in the operation management domain. The typical indicator used in the literature is greenhouse gas emissions. Some authors went a step further by attempting to capture a broader spectrum of sustainability dimensions. Mirzapour et al. [17] proposed an optimization 
model to aggregate production planning while integrating manufacturing operations. However, many simplified assumptions surround the modelling of environmental criteria including waste ratio calculations and the maximum allowed amount of greenhouse gas emissions. Wang et al. [18] used mixed linear programming to design a supply chain network while considering initial investments for environmental protection and carbon emissions during supply chain operations. They emphasized the role of managing the capacity to reduce the environmental impact of transportation and inventory level. A major challenge for integrating green considerations into supply chain management, including production management, relates to the gap between environmental sustainability assessment and optimization models, which primarily addresses the economic perspective (e.g., cost, lead time). This gap results in poor utilization of the relatively wellestablished environmental assessment tools for production management and supply chain management at large. For example, most optimization models to support decision-making for supply chain management and production management are based on very restrictive assumptions about the unit environmental impacts of the modelled products and processes [16,19]. Dekker et al. [16] reviewed the applications of operation research in green logistics. Their survey noted the lack of life cycle perspective in green operation optimization.

According to the United Nations Environment Programme, Life Cycle Thinking aims to manage the total life cycle of an organization's products and services towards more sustainable consumption and production [20]. Such an approach is based on preventive measures to reduce firms' environmental footprint and meet customer preferences throughout product life cycle. Life cycle assessment (LCA) took a lead in life cycle consideration as a well-established method in the literature. LCA is specified by the ISO 14040 series of standards and can be defined as a methodological framework for estimating and assessing the environmental impacts of a product life cycle [50]. The LCA phases are goal (i.e., explaining the goal and intended use of the results) and scope definition (i.e., modelling processes, output and input energy, and material flows), inventory analysis, impact assessment and interpretation (Fig. 1). The links of inventory data with impact categories are expressed through characterization factors [21]. An optional technique that is also applicable to indicators is 'normalization', which shows the relative importance of results related to a given region or reference (Rebitzer et al., 2004). LCA philosophy gave rise to several initiatives including Eco-Indicator 99 [22] and CML [23], which are two common environmental impact assessment methods. An overview of several assessment methods can be found in [24].

LCA has been widely applied to a variety of sectors including the textile industry and waste management and for different purposes including product development, strategic planning, and public policymaking [25]. Boufateh et al. [26] applied LCA to compare different products in the textile industry. They checked the applicability of several MCDM (multi-criteria decision making)

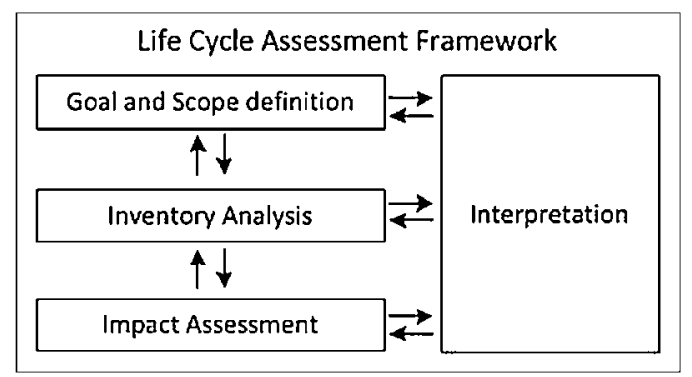

Fig. 1. LCA framework (Rebitzer et al., 2004). methods to ease the interpretation of the LCA results and highlighted the relevance of such methods. den Boer et al. [27] presented a decision support tool for assessing municipal waste management strategies from environmental, economic and social perspectives. The environmental perspective is particularly consistent with the LCA philosophy. The assessment spans over the phases of waste storage, collection, transport and treatment, and final disposal.

To simplify the assessment, software tools are used for modelling the subject of the assessment and fed by databases in which various calculation methods such as Ecoinvent are implemented [28]. Iosif et al. [29] developed a framework for integrating process modelling into LCA to simplify data collection and improve information reliability. The framework is specifically designed for steelmaking processes. Examples of the most common LCA modelling tools include SimaPro and Gabi. More recently, a set of integrated tools (named S-MC-S Editors) has been developed within the framework of the European FP7 project Sustainable MC-Mass Customization for Sustainability [30]. One specific characteristic of these tools lies in the integration of product, process and supply chain modelling with sustainability assessment. This initiative attempts to cover as many factors that impact sustainability as possible, which leads, however, to a more complex modelling process and high number of heterogeneous indicators, thus necessitating proper decision-making support.

\section{Business considerations in operation management}

Business concerns are largely addressed in the literature because they remain the mainspring of companies. Performance measurement is a common way to operationalize business goals [31-33]. Performance measurement (PM) is an activity aimed at reaching predefined goals [27] that are derived from the company's strategic objectives by using performance indicators (PIs) [34]. A PI is a variable that quantitatively expresses the effectiveness or efficiency, or both, of a part or whole of a process or system against a given norm or target [35]. PM represents the concrete formulation of a firm's strategic choices. Reviewing the actual versus planned measures allows areas of deficiency to be defined and thus corrective actions to be taken. The results may lead to adjustment of these goals. Performance measurement systems span over different functional areas within the company including management (e.g., specifying goals), process improvement (e.g., standards improvement), and factory shop floor (e.g., data collection and analysis) [36]. The most common performance indicators used in this context relate to costs, time, quality, flexibility, and productivity $[33,37]$. The ninth version of the SCOR (supply chain operations reference) model edited by the Supply Chain Council listed 5 key generic metrics for performance measurement-namely, Reliability, Responsiveness, Agility, Cost, and Asset Management. Reliability refers to the ability to deliver the right order to the right customer at the right place and time and in good condition. Responsiveness refers to the speed at which a supply chain provides products to the customer. Agility is defined by the degree of flexibility and adaptability of the supply chain. Cost refers to all costs associated with operating the supply chain. Asset Management is concerned with the effectiveness of an organization in managing assets to support demand satisfaction [38].

\section{Decision-making and indicator aggregation}

A critical challenge underlying decision-making in the sustainability context is the high number of indicators required to provide a comprehensive assessment of the economic and environmental impacts of the products and services included in the offering. 
Multi-criteria decision-making (MCDM) can be used to face this challenge because it models decision-makers' subjective assessments of many quantitative and qualitative criteria, which often conflict [39,40]. "The primary aim of MCDM is to develop a methodology that enables the aggregation of criteria/sub-criteria, which includes the preferences of decision-makers" [41, p. 98]. One of the most commonly used MCDM methods is the analytic hierarchy process (AHP) [42]. AHP evaluates the importance of various elements in relation to a goal based on relative comparisons. It is based on a hierarchical structure between criteria and thus shows some limitations regarding the analysis of the interactions between the compared elements. Despite these limits, the method continues to provide much support for the decision-making process. It can be applied to gather decision makers' preferences and aggregate them into an easy-to-read indicator system.

\section{Summary of the state of the art}

Offering variety in products and services proves to be a major concern for decision makers because it leads to increased costs and complexity within the production systems (cf. section "Impact of offering variety on products and product-service production systems"). Thus, the level of variety that a firm should deliver to the market must be exhaustively defined (cf. section "Green considerations in operation management"). Two decision levels emerge at this point: (i) how many variants should be included in the offering, and (ii) how much of each of the product variants should the company produce? The first relates to variety management, which aims to find an optimal product variety, and the second is concerned with variety steering, aiming at balancing the production among variants [13]. The focus of this paper is on variety steering while considering environmental and economic sustainability. In relation to this objective, the literature review underlined a gap between sustainability optimization models and life cycle assessment (cf. section "Business considerations in operation management"). Additional techniques such as AHP are seemingly suitable for the addressed multi-criteria decision-making problem (cf. section "Decision-making and indicator aggregation"). The next section reports on a model coupling MCDM and linear programming for steering variety towards environmental and economic sustainability.

\section{Proposed approach}

This section reports on a decision-making support approach for production planning that considers environmental sustainability criteria and customer demand. The aim is to balance the planned sales and production volumes among different variants included in the company's offering to minimize environmental impact and maximize the profit generated from the variants' sales. Fig. 2 shows the steps of the proposed approach. Step 1 is discussed in section "Selection of sustainability indicators". Steps 2 and 3 will be discussed in section "Indicator weighting". Steps 3 and 4 are described in section "Holistic sustainability measure". Step 5 is detailed in section "Linear programming model".

\section{Selection of sustainability indicators}

Because the focus of this paper is not in the indicator development, an existing set of indicators that meet the life cycle principles can be used. Within the limit of the current paper, a subset of the indicators described by $[43,44]$ is used to measure the economic output and environmental impact of a given product or service variant (UVC, GWP, NRD). However, these indicators do not consider the stock holding costs. Therefore, a new indicator, SHC (stock holding costs) is introduced (Table 1).

Although indicators are used basically to illustrate the methodological approach proposed in the paper, their selection is consistent with the following criteria:

- Comprehensive: indicators should cover a given solution space consisting of a product mix and its related processes and supply chain, and it should span over a life cycle perspective;

- Understandable: the indicator is easy to understand, even by people who are not experts;

- Exploitable and relevant: the indicator measures something that is important to the company implementing it for highlighting an existing problem;

- Established: definition and way to calculate indicators is desirable to show a large consensus in academic and industrial environments.

\section{Indicator weighting}

The number and heterogeneity of indicators are likely to impede the decision-making process. Prioritization is one way to address these issues because it provides the basis for building holistic measures, thus facilitating the decision-making process [45]. The weighting method adopted here is inspired by [46]. The method is based on interviews with company managers to capture their vision and priorities in terms of sustainability indicators. The interviews are supported by a document specifying the indicators and their definitions. Interviewees are then asked to run a pairwise comparison of these indicators. The interviewers are allowed to provide some guidance to the interviewee by asking questions using verbal appreciation to identify which criterion dominates the other-e.g., is Indicator 1 much more important than Indicator 2?

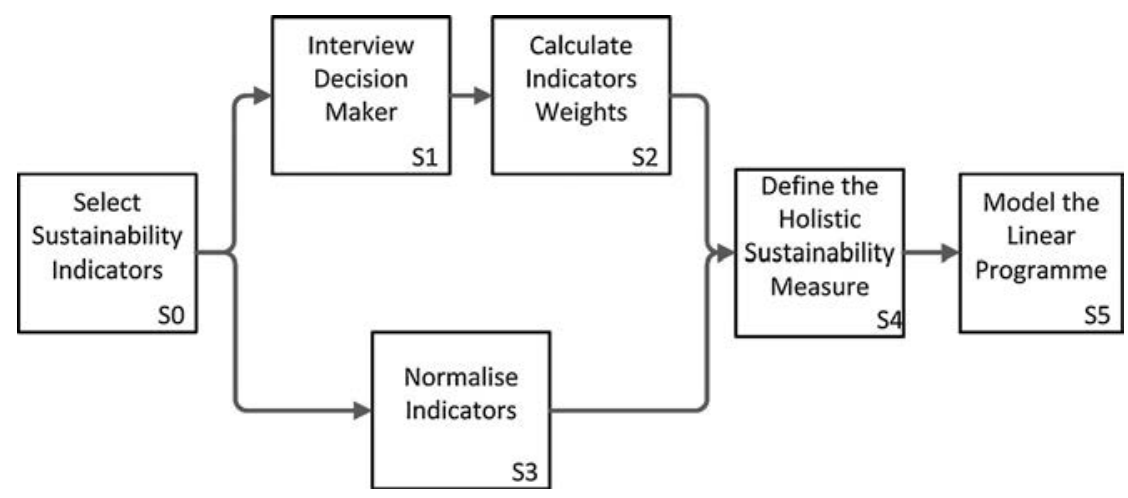

Fig. 2. Steps of the proposed approach. 
Table 1

Selected sustainability indicators.

\begin{tabular}{ll}
\hline Indicator & Definition \\
\hline $\begin{array}{c}U V C \text { - unitary variable } \\
\text { production cost }(€)\end{array}$ & $\begin{array}{l}\text { The } U V C \text { indicator measures the direct costs } \\
\text { (deducting overheads and taxes) related to the } \\
\text { manufacture of one product unit. }\end{array}$ \\
$\begin{array}{l}\text { The GWP } \\
\left.\text { potential (kg eq. } \mathrm{CO}_{2}\right)\end{array}$ & $\begin{array}{l}\text { to global warming caused by the emission of } \\
\text { greenhouse gases in the atmosphere. }\end{array}$ \\
$\begin{array}{l}\text { ThD-natural resources } \\
\text { depletion }(\mathrm{kg}\end{array}$ & $\begin{array}{l}\text { non-renewable abiotic natural resources. } \\
\text { antimony eq.) }\end{array}$ \\
$\begin{array}{c}S H C-\text { stock holding } \\
\text { costs }(€)\end{array}$ & $\begin{array}{l}\text { SHC measures the cost induced by holding one } \\
\text { unit of the stock during a given period of time. }\end{array}$ \\
\hline
\end{tabular}

Afterwards, the analytic hierarchy process (AHP) [42] is applied to the results of the comparison to derive weights of the indicators that reflect the firms' priorities. AHP and decision-making approaches at large help define trade-offs between environmental and economic criteria and company concerns [39,40].

The details of AHP application are as follows; assume that a predefined set of $n$ indicators $j$ are to be weighted. The pairwise comparison results in the matrix $P$ (Eq. (1)), where $\rho_{i j}$ is the relative importance of indicator $i$ over indicator $j$. The average value of normalized weights results in the weight of the indicator (Eq. (2)). The judgement scale adopted here is the one proposed by [42].

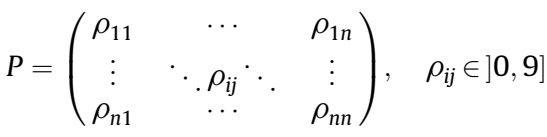

$\omega_{j}=\frac{\sum_{k=1}^{n}\left(\rho_{i j} / \sum_{l=1}^{n} \rho_{l j}\right)}{n}, \quad j \in\{1, \ldots, n\}$

\section{Holistic sustainability measure}

Because sustainability indicators are heterogonous in terms of measuring units and ranges of their values, normalization is needed to improve their readability and mitigate the complexity of analysing them. The normalization here uses an improved sigmoid function, as shown in Eq. (3). This function was chosen because it ensures pseudo-linear mapping of the original values (values between $x$ and $x_{\max }$ ) [47]. There are also other normalization methods that are more straightforward than the sigmoid function, such as Min-Max. However, unlike many of these approaches, the sigmoid function maps the input values into an open interval between 0 and 1 . This avoids the loss of the weight of the minimum in the input values, which conventionally mapped to 0 .

$\left.S(x)=\frac{1-b^{x / x_{\max }}}{a b^{x / x_{\max }}+1}, \quad S(x) \in\right] 0,1[$

with $a=2+\sqrt{ } 3$ and $b=7-4 \sqrt{ } 3$.

The subsequent holistic sustainability measure, $H$, is shown in Eq. (4). Such that $n U V C, n S H C, n G W P$, and $n N R D$ are the normalized values of the indicators $U V C, S H C, G W P$, and $N R D$, respectively.

$H=\omega_{U V C} \cdot(n U V C+n S H C)+\omega_{G W P} \cdot n G W P+\omega_{N R D} \cdot n N R D$

The lower $H(H>0)$ is, the more sustainable the product variant is. The improvement or deterioration of this holistic indicator is moderated by the component indicators' weights, which may enhance or mitigate the indicators' influence on $H$. As such, the holistic sustainability measure can be used to (i) track and improve the environmental and economic sustainability performance of a given system (e.g., mix of products and/or services, processes, and supply chain).

\section{Linear programming model}

To operationalize the holistic sustainability measure $(H)$ detailed in "Selection of sustainability indicators" and link it to a real company's context, a mathematical model is needed. Such a model would help introduce production- and market-related constraints and thresholds with the objective of the company to minimize the value of the holistic sustainability measure $(H)$. In this sense, the current subsection elaborates on a linear programming model that is detailed in the following.

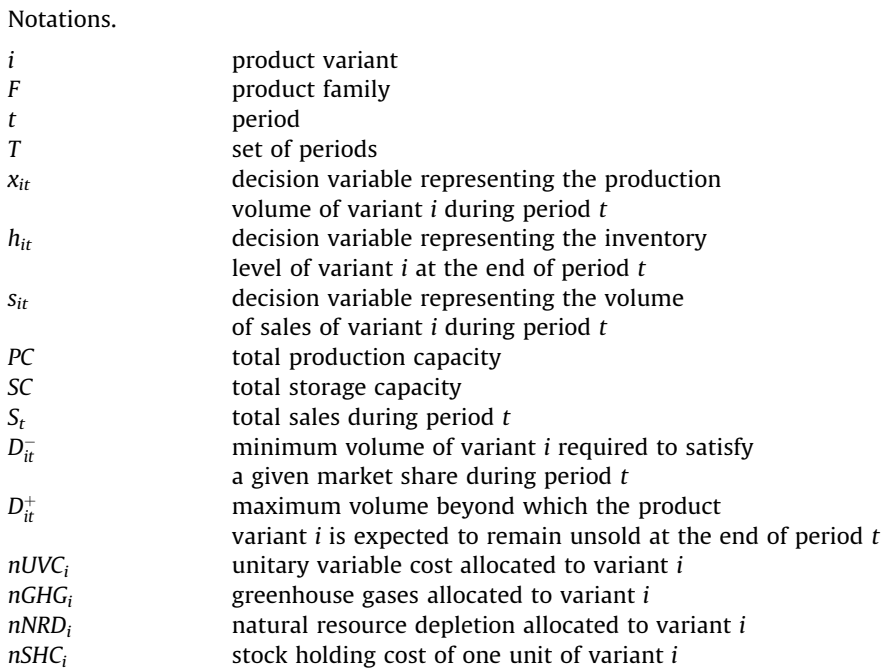

We consider a manufacturing firm aiming to balance the production volumes among variants belonging to a given product family. Starting from the holistic sustainability indicator $(H)$ defined in section "Selection of sustainability indicators", an objective function is given in Eq. (5) and must be minimized. This objective function represents the weighted sum of the convex functions relating to the three sustainability indicators [48]. We assume that most raw materials and components are ordered upon order confirmation, so we limit stock holding cost calculation to the finished products.

$$
\begin{aligned}
Z= & \sum_{i \in F} \sum_{t \in T}\left(\omega_{U V C} \cdot n U V C_{i}+\omega_{G W P} \cdot n G W P_{i}+\omega_{N R D} \cdot n N R D_{i}\right) \cdot x_{i t} \\
& +\omega_{U V C} \cdot n S H C_{i} \cdot h_{i t}
\end{aligned}
$$

The total production volume among variants should not exceed the total production capacity PC (Eq. (6)).

$\sum_{i \in F} x_{i t} \leq P C, \quad \forall t \in T$

The total inventory level at the end of given period should not exceed the storage capacity (Eq. (7)).

$\sum_{i \in F} h_{i t} \leq S C, \quad \forall t \in T$

The total production volume of a given variant augmented by its inventory level at the end of the previous period $t-1$ should equal the variant's sales during period $t$ augmented by the inventory level of this variant at the end of period $t$ (Eq. (8)).

$x_{i t}+h_{i t-1}=s_{i t}+h_{i t}, \quad \forall i \in F, \forall t \in T$ 
The expected sales volume of a given variant $s_{i t}$ during a given period should lie between the lower and upper thresholds of demand, $D_{i t}^{-}$and $D_{i t}^{+}$, respectively (Eq. (9)). The total expected sales volumes among variants during a given period are equal to $S_{t}$ (Eq. (10)).

$D_{i t}^{-} \leq s_{i t} \leq D_{i t}^{+}, \quad \forall i \in F, \forall t \in T$

$\sum_{i \in F} s_{i t}=S_{t}, \quad \forall t \in T$

The model can be written as follows:

$$
\begin{aligned}
& \quad \min Z \\
& \text { s.t. } \\
& \sum_{i \in F} x_{i t} \leq C, \quad \forall t \in T \\
& x_{i t}+h_{i t-1}=s_{i t}+h_{i t}, \quad \forall i \in F, \forall t \in T \\
& D_{i t}^{-} \leq s_{i t} \leq D_{i t}^{+}, \quad \forall i \in F, \forall t \in T \\
& x_{i t} \geq 0, \quad \forall i \in F, \quad \forall t \in T \\
& s_{i t} \geq 0, \quad \forall i \in F, \quad \forall t \in T \\
& h_{i t} \geq 0, \quad \forall i \in F, \forall t \in T
\end{aligned}
$$

Because variety allows broader market shares to be captured, the evaluation should also consider the profit associated with each solution proposed by the model. Therefore, a gross profit indicator is calculated as shown in Eq. (11).

$G P=\sum_{i \in F} \sum_{t \in T} P_{i} \cdot s_{i t}-U V C_{i} \cdot x_{i t}-S H C_{i} \cdot h_{i t}$

where $P_{i}, U V C_{i}$, and $S H C_{i}$ are the selling price, unitary variable cost and stock holding cost of variant $i$, respectively.

\section{Illustrative case study}

The specific example addressed in this section involves a physical product family. However, other case studies can be considered to check the application results of the proposed approach to integrated product service solutions.

\section{Data overview and underlying hypotheses}

The model is illustrated with an example inspired by a real case study in the furniture sector. The product family is a kitchen cabinet, which is a cornerstone of all kitchen variants regardless of the specific customers' requirements.

The data about the variants are fully gathered from the case company. Because data about available monthly production and storage capacities allocated to the considered product family were not available, estimates are used $(H 1, H 2, H 3)$. Similarly, an estimate of the stock holding ratio is used (H4). The aim is to analyze the production shares among variants proposed by the model to meet a given demand profile. Consequently, preliminary computations were run to eliminate the production capacity limitation constraints. More specifically, the production capacity was adjusted to cover the total demand of each period (i.e., expected sales) (H1). Regarding expected sales (cf. Table 2), only aggregate data are available, so the expected sales for the considered kitchen cabinet are derived based on its share of the

\begin{tabular}{|c|c|c|c|c|c|c|c|c|c|c|c|c|c|}
\hline \multirow[t]{3}{*}{$t$} & \multirow{3}{*}{$\begin{array}{l}\text { Expected } \\
\text { sales }\left(S_{t}\right)\end{array}$} & \multicolumn{12}{|c|}{ Demand } \\
\hline & & \multicolumn{2}{|l|}{1} & \multicolumn{2}{|l|}{2} & \multicolumn{2}{|l|}{3} & \multicolumn{2}{|l|}{4} & \multicolumn{2}{|l|}{5} & \multicolumn{2}{|l|}{6} \\
\hline & & $D^{-}$ & $D^{+}$ & $D^{-}$ & $D^{+}$ & $D^{-}$ & $D^{+}$ & $D^{-}$ & $D^{+}$ & $D^{-}$ & $D^{+}$ & $D^{-}$ & $D^{+}$ \\
\hline 1 & 300 & 10 & 20 & 10 & 20 & 10 & 20 & 115 & 125 & 10 & 20 & 115 & 125 \\
\hline 2 & 625 & 10 & 20 & 10 & 20 & 10 & 20 & 277 & 287 & 10 & 20 & 277 & 287 \\
\hline 3 & 885 & 39 & 49 & 39 & 49 & 39 & 49 & 349 & 359 & 39 & 49 & 349 & 359 \\
\hline 4 & 935 & 42 & 52 & 42 & 52 & 42 & 52 & 368 & 378 & 42 & 52 & 368 & 378 \\
\hline 5 & 985 & 44 & 54 & 44 & 54 & 44 & 54 & 388 & 398 & 44 & 54 & 388 & 398 \\
\hline 6 & 1260 & 58 & 68 & 58 & 68 & 58 & 68 & 499 & 509 & 58 & 68 & 499 & 509 \\
\hline 7 & 1360 & 63 & 73 & 63 & 73 & 63 & 73 & 539 & 549 & 63 & 73 & 539 & 549 \\
\hline 8 & 1375 & 64 & 74 & 64 & 74 & 64 & 74 & 544 & 554 & 64 & 74 & 544 & 554 \\
\hline 9 & 1260 & 58 & 68 & 58 & 68 & 58 & 68 & 499 & 509 & 58 & 68 & 499 & 509 \\
\hline 10 & 1425 & 66 & 76 & 66 & 76 & 66 & 76 & 564 & 574 & 66 & 76 & 564 & 574 \\
\hline 11 & 1355 & 63 & 73 & 63 & 73 & 63 & 73 & 537 & 547 & 63 & 73 & 537 & 547 \\
\hline 12 & 1250 & 57 & 67 & 57 & 67 & 57 & 67 & 495 & 505 & 57 & 67 & 495 & 505 \\
\hline
\end{tabular}
total expected sales (30\%).

- H1: Monthly production capacity amounts to 1300 units.

- H2: Monthly storage capacity amounts to 900 units.

- H3: There are no stocks kept from previous periods $(\forall i \in\{1, \ldots$, $\left.6\}, h_{i 0}=0\right)$.
Table 2

Total expected sales and demand distribution.

- H4: Unitary stock holding ratio is $0.3 \%$ of the article value.

The kitchen is sold as a whole; however, because of its modularity, the manager is able to provide an estimate of the single selling price of one kitchen cabinet. The estimates of the selling prices are similar for all variants, although this slightly simplistic because the price would depend on the level of customization of the cabinet. Notwithstanding, this allows a focus on the other indicators of cost and environmental dimensions because the variation in selling prices would impact the decision of the manager regarding variety steering.

\section{System modelling and indicator calculation}

Data collection allowed improvement in the understanding of the company offerings and ranges of its products. In collaboration with the SME manager, it was decided to focus on a single customized product: the kitchen cabinet. Accordingly, sustainability indicators must be calculated for a given kitchen cabinet. The goal is to provide a valuable and reliable input for the optimization regarding unit indicator values, consistently with the idea of bridging the gap between life cycle assessment and optimization models. In this sense, product mix (cf. left-hand side in Fig. 3), its related processes from the extraction until delivery (cf. middle of Fig. 3 (scope of the modelling)), and supply chain (cf. right-hand side in Fig. 3) must be included in the system modelling in such a way as to cover a broad range of impacts. These impacts will be reflected by the unit sustainability indicators that will be derived from the system modelling and are associated with the functional unit-namely, the kitchen cabinet.

The tools used for the modelling are developed within the framework of the S-MC-S project [30]. These modelling tools are connected to the Ecoinvent [28] database, which simplifies the calculation of both environmental and economic indicators using the same modelling instance. At the product level, the basic structure of the kitchen cabinet variants was modelled along with customization attributes (i.e., dimensions, handle type) and their occurrence probabilities. As mentioned before, the current case study considers 6 variants of the kitchen cabinet, whose main differentiating features are the dimensions of the panels and material and shape of the handle. At the process level, the list of activities contributing to the realization of the cabinet was identified and modelled (e.g., wood cutting, edging, assembly) including unitary costs and respective standard processes identified in the Ecoinvent database [28]. Finally, the supply chain of the kitchen cabinet was modelled including the suppliers and markets to consider (i) the transportation data and (ii) the unit purchasing costs when calculating the indicators during the subsequent step. The UVC, GWP, and NRD indicators were calculated out of the above 

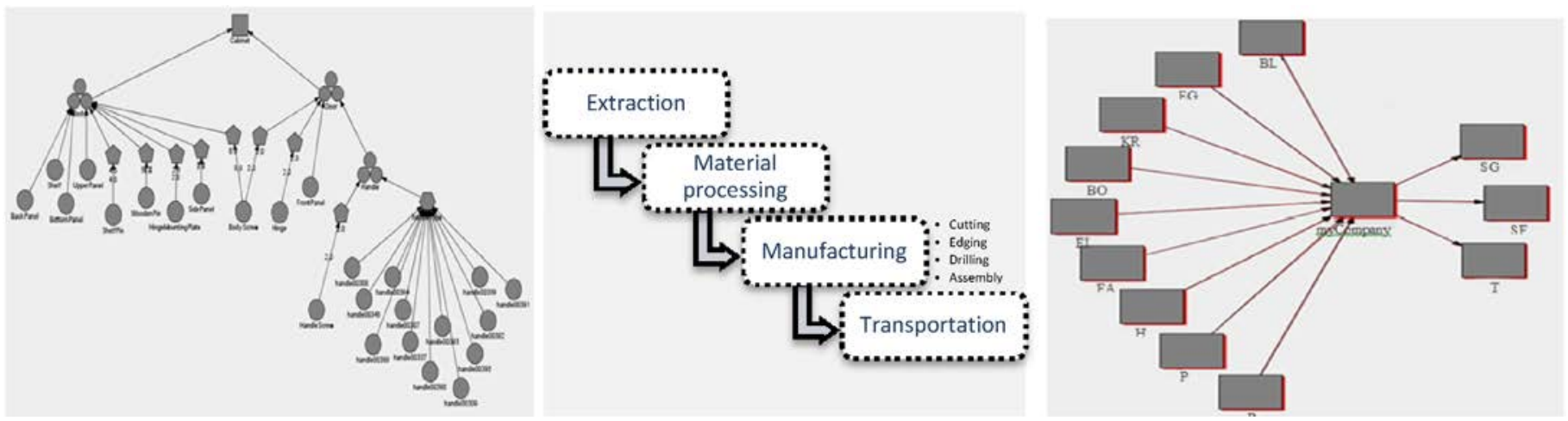

Fig. 3. System modelling.

modelling, and the subsequent values are shown in Table 3, where the last column of the table includes the selling prices of the variants.Table 4 shows the weights of the indicators derived from interview outputs. The weights reflect the concerns of the firm, which are dominated by the economic perspective (UVC weight). Unsurprisingly, the GWP has the lowest weight, which can be explained by the fact that for the manager, there is no direct impact of the greenhouse gas emissions on costs. The NRD indicator, however, is weighted more than GWP, which pertains to the relatively strong correlation between resource consumption and total costs. In the end, the manager decisions are cost-driven although environmental considerations are put forth as a priority for the company. The normalization results of the indicators are shown in Table 5.

\section{Optimal production planning according to sustainability criteria}

The model was implemented using the software application LINGO 15.0.20 and run on an Intel Core processor at $2.40 \mathrm{GHz}$. The model includes 216 variables and 469 constraints. Tables 6 and 7 show the indicator values and the sales distribution, respectively, as suggested by the model.

To track the extent to which the model maximizes the sales of each of the variants, we calculate a distance from the upper threshold of the expected demand $\left(D_{\max }^{i}\right)$ throughout the planning horizon, according to Eq. (12).

$\forall i \in\{1, \ldots, 6\}, \quad D_{\max }^{i}=1-\frac{S}{D_{i}^{+}}$

where $i$ refers to the variant, $S$ refers to the total sales throughout the planning horizon $\left(S=\sum_{t=1}^{12} s_{i t}\right)$, and $D_{i}^{+}$is the total demand of variant $i$ throughout the planning horizon.

Table 8 reports on the correlation between the distance to the maximum and the normalized unit indicators. The value of $n S H C$ remains the same over the six variants, so it was excluded from the correlation analysis. It can be observed that the maximization of the variant sales share is more closely correlated with $n U V C$ and $n S H C$ than $n N R D$ and $n G W P$. This means that the economic criterion

Table 3

Unit indicator values for the kitchen cabinet

\begin{tabular}{llllll}
\hline Variant & UVC & GWP & NRD & SHC & $P$ \\
\hline 1 & 11.21 & 20.95 & 0.19 & 10.5 & 350 \\
2 & 13.41 & 23.56 & 0.22 & 10.5 & 350 \\
3 & 14.35 & 22.84 & 0.21 & 10.5 & 350 \\
4 & 13.80 & 22.36 & 0.21 & 10.5 & 350 \\
5 & 16.10 & 23.07 & 0.22 & 10.5 & 350 \\
6 & 14.86 & 22.10 & 0.21 & 10.5 & 350 \\
\hline
\end{tabular}

remains the main driver of the planning problem solution, which is consistent with the foregoing discussion of the manager weighting (cf. section "Data overview and underlying hypotheses"). The table also shows a relatively strong correlation between $n N R D$ and $n U V C$, which numerically explains the intuitive choices of the manager where $N R D$ is weighted more than GWP.

Fig. 4 shows the production volumes of the different variants, cumulated sales and inventory through the planning horizon. Variants 4 and 6 have the majority of production volumes consistently with the suggested sales volumes, which in turn are in line with the upper and lower demand thresholds (cf. Table 1). To minimize costs incurred by holding inventories, the model postpones the production as much as possible while respecting the due dates (i.e., sales). This explains why there is no inventory kept during the first periods; the production volume per period covers the expected sales for the given period.

\section{Discussion}

The case study shows how the proposed model balances sales volumes among different product variants towards a more environmentally friendly and profitable offering. The subsequent production volumes required to meet the suggested sales are balanced throughout the computation periods while considering the environmental and economic objectives. As such, the model can be used to support the decision-making to answer the question of how much of each product or service variant the company should produce by identifying trade-offs between rather conflicting criteria. Furthermore, the model uses inputs from the decision makers to weigh the indicators, which is likely to facilitate its adoption by practitioners. As such, the weighting and normalization helped combine several criteria towards a common goal, which is sustainability. In fact, one of the major issues regarding actual utilization of environmental sustainability indicators is their high number and heterogeneity. The decision makers, particularly in SMEs, end up relying on their intuitive choices, which are rather cost-driven. Consequently, weighting the indicators provides support for the decision maker and most importantly shows them their real priorities regarding environmental and economic

Table 4

Indicator weights.

\begin{tabular}{ll}
\hline Indicator & Weight \\
\hline UVC & 0.53 \\
GWP & 0.07 \\
NRD & 0.40 \\
\hline
\end{tabular}


Table 5

Normalized indicator values.

\begin{tabular}{lllll}
\hline Variant & nUVC & $n G W P$ & $n N R D$ & $n S H C$ \\
\hline 1 & 0.60 & 0.69 & 0.19 & 0.88 \\
2 & 0.67 & 0.73 & 0.22 & 0.88 \\
3 & 0.69 & 0.72 & 0.21 & 0.88 \\
4 & 0.68 & 0.71 & 0.21 & 0.88 \\
5 & 0.73 & 0.72 & 0.22 & 0.88 \\
6 & 0.70 & 0.71 & 0.21 & 0.88 \\
\hline
\end{tabular}

dimensions of sustainability. Thus, the proposed weighting method can be used as a self-assessment tool by decision makers.

Perspectives for further improvement include the integration of the profit indicator in the objective function to broaden the scope of the identified trade-offs. However, one issue at this point relates to the weighting step. In fact, it is critical to judge priorities of profit compared with environmental issues because the mainspring of a company is typically to generate profit. The paper has also contributed towards bridging the gap between life cycle considerations and supply chain optimization. However, the path is still long: for instance, many data are often required to perform even a simple LCA. Additionally, LCA data are underpinned by much uncertainty for several reasons such as the region/country where the data are collected and the differences between reference processes and the designed ones.

The combination of the cost and environmental indicators simplifies the decision-making by finding optimal solutions that meet the company's priorities. The combination of these heterogeneous criteria leads to a loss of comprehensiveness to some extent. In fact, the holistic indicator resulting from combining weights and normalized indicators (cf. section "Selection of sustainability indicators", Eq. (4)) may have the same values in completely different situations because (i) the weights may compensate for the normalized indicator values and vice versa, and (ii) the indicators can compensate for the values of each other. This problem can be approached in different ways: (i) computing the values of the single indicators for a given optimal value of the holistic indicator to track the impact of the offering from different perspectives; (ii) adapting the mathematical model, particularly the objective function, to accommodate the heterogeneity of the criteria; (iii) setting up predefined targeted indicator values, then computing the rate of computed indicator values to the targeted values, so that the model would track the distance from

Table 6

Indicator values.

\begin{tabular}{llll}
\hline$U V C^{\mathrm{a}}(€)$ & GWP (kg eq. $\left.\mathrm{CO}_{2}\right)$ & NRD (kg antimony eq.) & $G P(€)$ \\
\hline 185629 & 290212 & 2732 & 4359034 \\
\hline
\end{tabular}

a UVC includes the stock holding costs.

Table 7

Sales volumes.

\begin{tabular}{rllllll}
\hline \multicolumn{1}{c}{$t$} & $s_{1 t}$ & $s_{2 t}$ & $s_{3 t}$ & $s_{4 t}$ & $s_{5 t}$ & $s_{6 t}$ \\
\hline 1 & 20 & 20 & 10 & 125 & 10 & 115 \\
2 & 20 & 20 & 11 & 287 & 10 & 277 \\
3 & 49 & 49 & 40 & 359 & 39 & 349 \\
4 & 52 & 52 & 43 & 378 & 42 & 368 \\
5 & 54 & 54 & 47 & 398 & 44 & 388 \\
6 & 68 & 68 & 58 & 509 & 58 & 499 \\
7 & 73 & 73 & 63 & 549 & 63 & 539 \\
8 & 74 & 74 & 65 & 554 & 64 & 544 \\
9 & 68 & 68 & 58 & 509 & 58 & 499 \\
10 & 76 & 76 & 69 & 574 & 66 & 564 \\
11 & 73 & 72 & 63 & 547 & 63 & 537 \\
12 & 57 & 67 & 67 & 505 & 57 & 497 \\
\hline
\end{tabular}

Table 8

Correlation between $D$-max and indicators.

\begin{tabular}{lllll}
\hline & $D-\max$ & $n U V C$ & $n N R D$ & $n G W P$ \\
\hline$D$-max & 1 & & & \\
$n U V C$ & 0.587 & 1 & & \\
$n N R D$ & 0.341 & 0.838 & 1 & 1 \\
$n G W P$ & 0.324 & 0.683 & 0.935 & \\
\hline
\end{tabular}

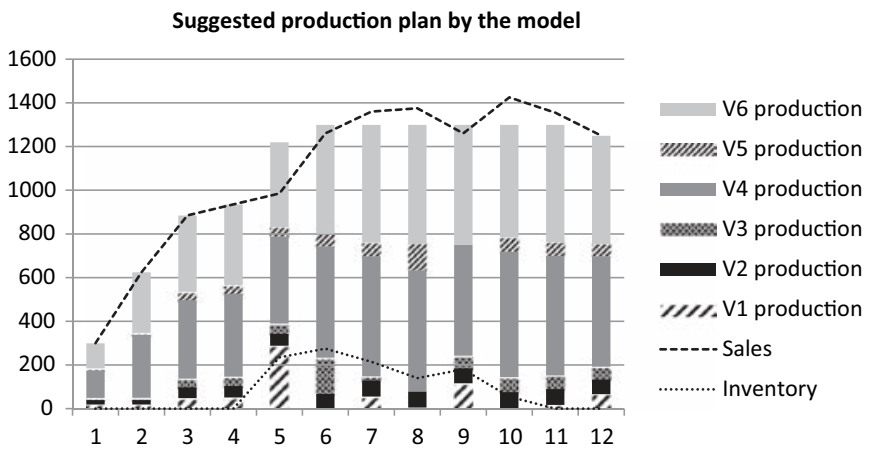

Fig. 4. Solution summary.

sustainability objectives. Clearly, this opens up another improvement area of the proposed approach.

Beyond the technical aspects, the ultimate goal of the proposed approach is to reinforce the win-win perspective of adopting green practices in manufacturing firms. Green considerations in variety steering not only allow reduced environmental impact of the products and services included in the offering but can also generate economic value for the company for two main reasons. First, the so-called green products are generally more attractive than those with "high" environmental impact. Second, depending on the context of the companies, carbon taxes may be applied and introduce new opportunities for cost reduction. The rationale underlying the carbon taxes is that companies receive a certain carbon emission allowance (i.e., threshold). They must buy or sell a given amount of carbon emissions according to their effective emissions during a given period of time [49]. As such, these taxes motivate companies to engage in sustainable development because it compels them to jointly optimize both economic and environmental performance. In this regard, the win-win perspective implies that laws and regulations should be seen as opportunities for cost reduction and/or margin increase rather than development constraints.

\section{Conclusion}

This paper proposes an approach relying on weighting, normalization and optimization to support decision-making on variety levels from a production planning perspective. It was illustrated by an example inspired from a real case. The example showed how the proposed approach can be used in practice. It was observed that the model combines indicator weights and values allocated to product or service variants towards the identification of trade-offs. Additionally, the model optimizes the production volumes and inventory levels, thus providing useful support for production planning for variety steering.

\section{References}

[1] Pine, J., 1993, Mass Customization: The New Frontier in Business Competition, Harvard Business School Press, Boston. 
[2] Meier, H., Roy, R., Seliger, G., 2010, Industrial Product-service Systems-IPS2, CIRP Annals - Manufacturing Technology, 59/2: 607-627.

[3] Ulrich, K., 1995, The Role of Product Architecture in the Manufacturing Firm, Research Policy, 24/3: 419-440.

[4] Beuren, F.-H., Gomes-Ferreira, M.G., Cauchick-Miguel, P.-A., 2013, Productservice Systems: A Literature Review on Integrated Products and Services, Journal of Cleaner Production, 47:222-231.

[5] Goedkoop, M.J., Halen, C.J.G., van Riele, H.R.M., Rommens, P.J.M., 1999, Product Service Systems, Ecological and Economic Basics, The Hague, NL.

[6] Nishino, N., Takenaka, T., Koshiba, H., Kodama, K., 2014, Customer Preference Based Optimization in Selecting Product/Service Variety, CIRP Annals Manufacturing Technology, 63/1: 421-424.

[7] Medini, K., Boucher, X., 2015, Decision Making Support to Steer Offering Variety During Production Planning, Procedia CIRP.

[8] Samy, S., ElMaraghy, H., 2010, A Model for Measuring Products Assembly Complexity, International Journal of Computer Integrated Manufacturing, 23/ 11: 1015-1027

[9] Feng, T., Zhang, F., 2013, The Impact of Modular Assembly on Supply Chain Efficiency, Production and Operations Management, 23/11: 1985-2001.

[10] Chandra, C., Kamrani, A.K., 2004, Mass Customization: A Supply Chain Approach, Springer Science + Business Media, New York

[11] Yao, J., Liu, L., 2009, Optimization Analysis of Supply Chain Scheduling in Mass Customization, International Journal of Production Economics, 117/1 197-211.

[12] Brunoe, T., Nielsen, K., Taps, S.B., Jørgensen, K.A., 2013, Sustainability Evaluation of Mass Customization, IFIP WG 5.7 International Conference-Advances in Production Management Systems (APMS 2013), Springer, Pennsylvania.

[13] Blecker, T., Abdelkafi, N., Kaluza, B., Friedrich, G., 2006, Controlling Varietyinduced Complexity in Mass Customisation: A Key Metrics-based Approach, International Journal of Mass Customization, 1/2-3: 272-298.

[14] Gardner, D., 2009, Mass Customization: How Build to Order, Assemble to Order, Configure to Order, Make to Order, and Engineer to Order Manufacturers Increase, California,

[15] Neto, Q.F., Walther, G., Bloemhof, J., van Nunen, J., Spengler, T., 2009, A Methodology for Assessing Eco-efficiency in Logistic Networks, European Journal of Operational Research, 193/3: 647-914.

[16] Dekker, R., Bloemhof, J., Mallidis, I., 2012, Operations Research for Green Logistics-An Overview of Aspects, Issues, Contributions and Challenges, European Journal of Operational Research, 219/3: 671-679.

[17] Mirzapour, S.M.J., Baboli, A., Sazvar, A., 2013, A Stochastic Aggregate Production Planning Model in a Green Supply Chain: Considering Flexible Lead Times, Nonlinear Purchase and Shortage Cost Functions, European Journal of Operational Research, 230/1: 26-41.

[18] Wang, F., Lai, X., Shi, N., 2011, A Multi-objective Optimization for Green Supply Chain Network Design, Decision Support Systems, 51/2: 262-269.

[19] Sbihi, A., Eglese, R.W., 2007, Combinatorial Optimization and Green Logistics, 4OR: A Quarterly Journal of Operations Research, 5/2: 99-116.

[20] UNEP. 2006, UNEP Guide to Life Cycle Management, UNEP, Belgium.

[21] Pennington, D., Potting, J., Finnveden, G., Lindeijer, E., Jolliet, O., Rydberg, T., Rebitzer, G., 2004, Life Cycle Assessment. Part 2: Current Impact Assessment Practice, Environment International, 30/5: 721-739.

[22] Goedkoop, M., Spriensma, R., 2001, The Eco-Indicator 99: A Damage Oriented Method for Life Cycle Impact Assessment-Methodology Annex, PRé Consultants, Amersfoort, Netherlands.

[23] Guinée, J.B., Gorrée, M., Heijungs, R., Huppes, G., Kleijn, R., Koning, A.D., Oers, L.V., Wegener Sleeswijk, A., Suh, S., Udo de Haes, H.A., Bruijn, H.D., Duin, R.V., Huijbregts, M.A.J., 2002, Handbook on Life Cycle Assessment, Operationa Guide to the ISO Standards, Dordrecht, Netherlands.

[24] Acero, A.P., Rodríguez, C., Ciroth, A., 2014, Impact Assessment Methods in Life Cycle Assessment and Their Impact Categories, GreenDelta, Berling, Germany

[25] Heijungs, R., Huppes, G., Guinée, J., 2010, Life Cycle Assessment and Sustainability Analysis of Products, Materials and Technologies. Toward a Scientific Framework for Sustainability Life Cycle Analysis, Polymer Degradation and Stability, 95/3: 422-428.
[26] Boufateh, I., Perwuelz, A., Rabenasolo. Jolly, A.-M., 2011, Multiple Criteria Decision Making for Environmental Impacts Optimization, International Journal of Business Performance and Supply Chain Modelling, 3/1: 28-42.

[27] den Boer, J., den Boer, E., Jager, J., 2007, LCA-IWM: A Decision Support Tool for Sustainability Assessment of Waste Management Systems, Waste Management, 27/8: 1032-1045

[28] Weidema, B.P., Bauer, C., Hischier, R., Mutel, C., 2013, Ecoinvent ReportOverview and Methodology, The Ecoinvent Centre, St. Gallen.

[29] Iosif, A., Hanrot, F., Ablitzer, D., 2008, Process Integrated Modelling for Steelmaking Life Cycle Inventory Analysis, Environmental Impact Assessment Review, 28/7: 429-438.

[30] Pedrazzoli, P., Alge, M., Bettoni, A., Canetta, L., 2012, Modeling and Simulation Tool for Sustainable MC Supply Chain Design and Assessment, APMS, Rhodes, Greece

[31] Tan, K.H., Rae, R.H., 2009, Uncovering the Links Between Regulation and Performance Measurement, International Journal of Production Economics, 122/1: 449-457.

[32] Braz, R.G.F., Scavarda, L.F., Martins, R.A., 2011, Reviewing and Improving Performance Measurement Systems: An Action Research, International Journal of Production Economics, 133/2: 751-760.

[33] Folan, P., Browne, J., 2005, A Review of Performance Measurement: Towards Performance Management, Computers in Industry, 56/7: 663-680.

[34] Lohman, C., Fortuin, L., Wouters, M., 2004, Designing a Performance Measurement System: A Case Study, European Journal of Operations Research, 156/2: 267-286.

[35] Fortuin, L., 1988, Performance Indicators-Why Where and How? European Journal of Operations Research, 34/1: 1-9.

[36] Ghalayini, A.M., Noble, J.S., Crowe, T.J., 1997, An Integrated Dynamic Performance Measurement System for Improving Manufacturing Competitiveness, International Journal of Production Economics, 48/3: 207-225.

[37] Brewer, P., Speh, T., 2001, Adapting the Balanced Scorecard to Supply Chain Management, Supply Chain Management Review, 5/2: 48-56.

[38] Supply Chain Council. 2008, SCOR-Supply Chain Operations Reference Model-Version 9.0, Supply Chain Council, USA.

[39] Dey, P.K., Cheffi, W., 2012, Green Supply Chain Performance Measurement Using the Analytic Hierarchy Process: A Comparative Analysis of Manufacturing Organisations, Production Planning and Control, 24/8-9: 702-720.

[40] Bhattacharya, A., Mohapatra, P., Kumar, V., Dey, K.P., Brady, M., Tiwari, M.K., Nudurupati, S.S., 2013, Green Supply Chain Performance Measurement Using Fuzzy ANP-based Balanced Scorecard: A Collaborative Decision-making Approach, Production Planning and Control, .

[41] Mandic, K., Bobar, V., Delibasic, B., 2015, Modeling Interactions Among Criteria in MCDM Methods: A Review, Decision Support Systems V-Big Data Analytics for Decision Making,

[42] Saaty, T.L., 2008, Decision Making with the Analytic Hierarchy Process, International Journal Services Sciences, 1/1: 83-98.

[43] Medini, K., A.B.. Fontana, A., Corti, D., Zebardast, M., 2011, S-MC-S-D3.1 Assessment Model, European Commission: 503

[44] Boer, C.R., Pedrazzoli, P., Bettoni, A., Sorilini, M., 2013, Mass Customization and Sustainability, Springer, New York.

[45] Harik, R., El Hachem, W., Medini, K., Bernard, A., 2015, Towards a Holistic Sustainability Index for Measuring Sustainability of Manufacturing Companies, International Journal of Production Research, 53/13: 4117-4139.

[46] Medini, K., Da Cunha, C., Bernard, A., 2015, Tailoring Performance Evaluation to Specific Industrial Contexts-Application to Sustainable Mass Customisation Enterprises, International Journal of Production Research, 53/8: 2439-2456.

[47] De Marsico, M. Nappi, M., Riccio, D., Tortora, G., 2011, NABS: Novel Approaches for Biometric Systems, IEEE Transactions in Systems Man and Cybernetics Part C: Applications and Reviews, 41/4: 481-493.

[48] Ehrgott, M.A., 2013, A Discussion of Scalarization Techniques for Multiple Objective Integer Programming, Annals of Operations Research, 147/1: 343-360.

[49] EP \& CEU. 2009, Directive 2009/29/EC of the European Parliament and of the Council of 23 April 2009, Official Journal of the European Union,

[50] Rebitzer, G., Ekvall, T., Frischknecht, R., Hunkeler, D., Norris, G., Rydberg, T., et al, 2004, Life cycle assessment part 1: framework, goal and scope definition, inventory analysis, and applications, Environment International, 30/5: 701-720. 